\title{
KRISTAL CAIR LAMELAR DALAM SISTEM AIR, TETRA ETILEN GLIKOL DODESIL ETER, DAN TEMBAGA NITRAT
}

\author{
Ali Amran \\ Jurusan Kimia FMIPA Universitas Negeri Padang
}

\begin{abstract}
The lamellar liquid crystal in water, tetraethyleneglycol dodecylether, and copper nitrate system has been investigated. The results which characterized using optical polarizing microscope and smallangle $x$-ray diffraction showed the stability of the liquid crystal region was $40 \%$ and $65 \%$ by weight of surfactant. The interlayer spacing of lamellar liquid crystal, with and without various concentrations of copper nitrate content, remained constant.
\end{abstract}

Keywords : Lamellar liquid crystal, Tetraethylene glycol dodecylether, Copper nitrate, Optical polarizing microscope, Small-angle x ray diffraction

\section{PENDAHULUAN}

Larutan berair dan tidak berair dari surfaktan $^{[1,2,3,4]}$ akan membentuk fasa kristal cair liotropik yang berbeda sebagai hasil interaksi di antara struktur asosiasi atau aggregasi misel. Fasa ini memiliki sifat yang statis dan dinamis terkait dengan keadaan kristal dan cairan. Pemahaman tentang struktur dan fasa dinamis dari fasa liotropik atau kristal cair adalah amat penting dari segi fandamental dan praktis, terutama berbagai aplikasinya dalam berbagai bidang, seperti detergen ${ }^{[5]}$, $\operatorname{kosmetik}^{[6]}$ farmasi ${ }^{[7,8]}$, emulsi ${ }^{[9]}$. Selain itu, diagram fasa dari surfaktan non-ionik polioksietilen menunjukkan suatu rangkaian fasa kristal-cair liotropik yang berbeda ${ }^{[10,11,12]}$.

Jenis struktur kristal cair yang terbentuk tergantung pada kulvatur yang diadopsi oleh interfasa di antara agregat dan pelarut di selilingnya. Fase lamelar, heksagonal dan kubik adalah fase yang umum dalam sistem ini. Fase liotropik lamelar, $\mathrm{L} \alpha$, muncul pada konsentrasi yang cukup tinggi apabila interfasa cenderung menjadi planar, meskipun surfaktan dengan rantai hidrofobik yang muncul pada konsentrasi rendah. Fasa ini terdiri dari kristal dimensi-satu sederhana tersusun dari lapisan pengganti dari air dan bilayer surfaktan dengan karakteristik polikristal.

\section{METODOLOGI}

Bahan kimia yang dipergunakan tanpa pemurnian lebih lanjut yaitu Macol LA4 (tetraetilglikol dodesileter, dari Mazer Chemicals), sikloheksana $(100 \%$, dari J. T. Baker). Asam nitrat (70\% ACS certified, Baxter Healthcare Corp., Scientific Product Division) digunakan untuk memperoleh $\mathrm{pH}$ air $=1,30$, dan $\mathrm{Cu}(\mathrm{NO})_{3} \cdot 2,5 \mathrm{H}_{2} \mathrm{O}$ dari Fisher Scientific. Air yang digunakan adalah deionisasi dan disuling.

Diagram fasa kristal cair lamelar dalam sistem air, surfaktan dan garam tembaga nitrat (Gambar 1) diperoleh dengan mengaduk campuran surfaktan dan larutan tembaga nitrat $(0 ; 8,1 ; 16,1 ; 24,2 ; 32,3 ; 40,1 ; 48,4$; dan $56,5 \%$ $w / w)$. Diagram fasa ditentukan dengan observasi visual menggunakan Optical Polarizing Microscope, dan dikonfirmasikan dengan hasil difraksi dari small-angle $x$-ray diffraction (Siemens Crystalloflex 4) dengan Tennelec detector system (Model PSD 100).

\section{HASIL DAN PEMBAHASAN}

Diagram fasa kristal cair lamelar dalam sistem air, surfaktan dan garam tembaga nitrat dengan konsentrasi yang tinggi dinyatakan dalam Gambar $1^{[13]}$. Pada gambar terlihat bahwa stabilitas daerah kristal cair lamelar berada pada $40 \%$ sampai $65 \%$ berat surfaktan. 
Hasil pengukuran Interlayer Spacing $\left(\mathrm{A}^{\circ}\right)$ kristal cair lamelar dan Rasio Volume (Volume Ratio) dari larutan tembaga nitrat terhadap surfaktan dinyatakan dalam Tabel 1. Lebih lanjut, data Tabel 1 ditampilkan dalam Gambar 2.

Kurva linier atau garis lurus yang diperoleh (Gambar 1) adalah sesuai dengan hubungan $\mathrm{d}$ $=\mathrm{d}_{0}[1+(1-\alpha) R]$, di mana $\mathrm{d}$ adalah interlayer spacing, $\mathrm{d}_{0}$ harga interlayer spacing dari hasil ekstrapolasi untuk $R=0, \alpha$ adalah penetrasi, dan $R$ adalah rasio volume. Dari Gambar 1, diperoleh tingkat penetrasi $(\alpha)$ sebesar $12 \%$. Hasil ini lebih rendah dari hasil penelitian terdahulu ${ }^{[14]}$, di mana untuk surfaktan yang sama, diperoleh tingkat penetrasi $13 \%$. Dengan menggunakan estimasi ${ }^{[15]}$, diperoleh panjang rantai efektif kristal cair lamelar (4 grup etilen oksida) adalah $16,2 \mathrm{~A}^{\circ}$ (seharusnya $18,0 \mathrm{~A}^{\circ}$ ), di mana kontribusi dari rantai polar dan non-polar kelihatannya masuk akal. Terbukti bahwa dengan terlarutnya tembaga nitrat sampai konsentrasi tinggi $56,5 \% \mathrm{w} / \mathrm{w}$ tidak merubah konformasi rantai polietilen oksida. Toleransi struktur kristal cair terhadap kadar garam nitrat yang tinggi memiliki efek yang relatif kecil terhadap kestabilan kristal cair lamelar. Selain itu, partikel tembaga(I)nitrat yang diperoleh dari struktur lain ${ }^{[16]}$ tidak ada dalam kasus ini.

Pola kristal cair lamelar yang diobservasi dengan Optical Polarizing Microscope dinyatakan seperti Gambar 3.

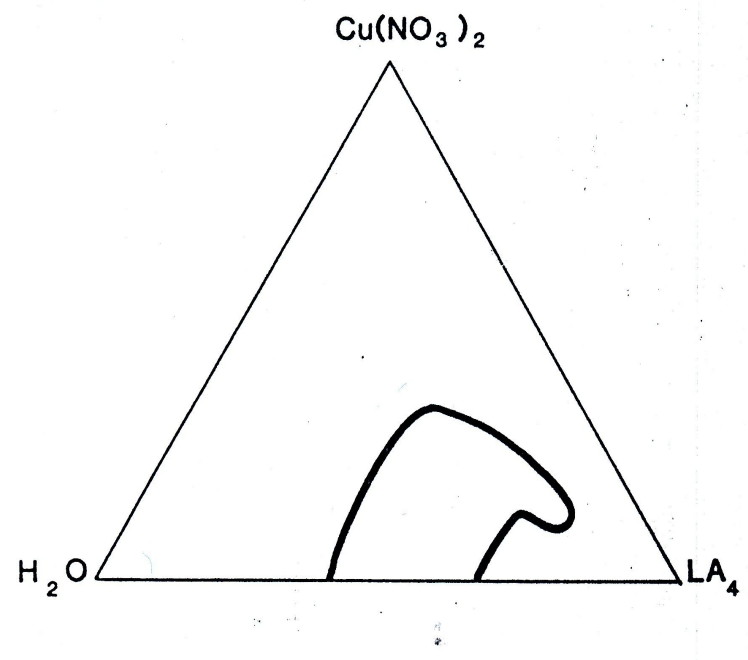

Gambar 1. Diagram fasa kristal cair lamelar dalam sistem air, surfaktan dan garam tembaga nitrat

Tabel 1. Interlayer Spacing( $\left.\mathbf{A}^{0}\right)$ Kristal Cair Lamelar dan Rasio Volume (R) Larutan Tembaga Nitrat terhadap Surfaktan

\begin{tabular}{ccccccc}
\hline \multirow{2}{*}{$\begin{array}{c}\text { Tembaga Nitrat } \\
(\% \mathrm{w} / \mathrm{w})\end{array}$} & \multicolumn{6}{c}{$\mathrm{x} / \mathrm{y}\left[\mathrm{x}=\right.$ Interlayer Spacing $\left(\mathrm{A}^{\circ}\right)$ dan $\mathrm{y}($ Rasio Volume, $\left.\mathrm{R})\right]$} \\
\cline { 2 - 7 } & 1 & 2 & 3 & 4 & 5 & 6 \\
\hline 0,0 & $51 / 0,50$ & $53 / 0,60$ & $59 / 0,80$ & $65 / 0,93$ & $69 / 1,1$ & $75 / 1,40$ \\
8,1 & $45 / 0,35$ & $52 / 0,70$ & $57 / 0,80$ & $61 / 0,90$ & $68 / 1,05$ & $74 / 1,30$ \\
16,2 & $44 / 0,35$ & $48 / 0,50$ & $55 / 0,70$ & $65 / 0,95$ & $69 / 1,10$ & $76 / 1,35$ \\
24,3 & $42 / 0,25$ & $49 / 0,45$ & $52 / 0,60$ & $56 / 0,75$ & $61 / 0,90$ & $69 / 1,10$ \\
32,4 & $46 / 0,40$ & $49 / 0,45$ & $52 / 0,55$ & $56 / 0,70$ & $60 / 0,85$ & $65 / 0,95$ \\
40,5 & $40,5 / 0,20$ & $46 / 0,40$ & $49 / 0,50$ & $54 / 060$ & $58 / 0,75$ & $65 / 0,95$ \\
48,6 & $39 / 0,20$ & $42 / 0,25$ & $46 / 0,40$ & $52 / 0,60$ & $56 / 0,75$ & $60 / 0,90$ \\
56,7 & $38 / 1,15$ & $43 / 0,30$ & $48 / 0,45$ & $55 / 0,70$ & $60 / 0,85$ & $66 / 1,10$ \\
\hline
\end{tabular}




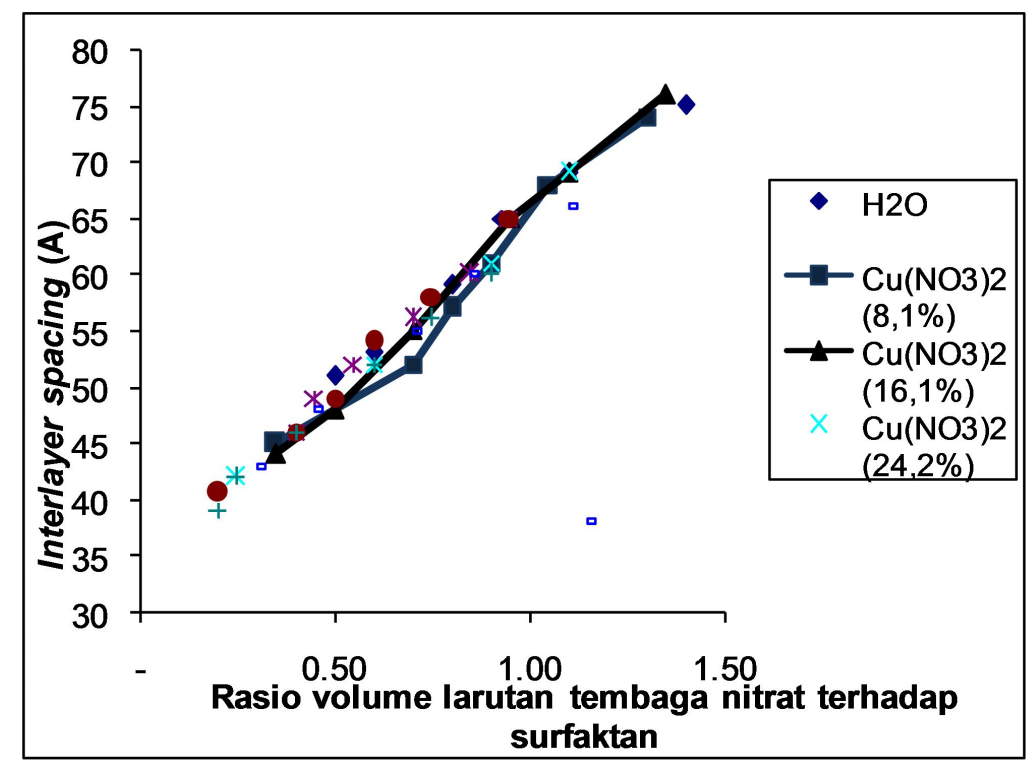

Gambar 2. Hubungan antara Interlayer Spacing $\left(\mathrm{A}^{\circ}\right)$ dan rasio volume tembaga nitrat terhadap surfaktan
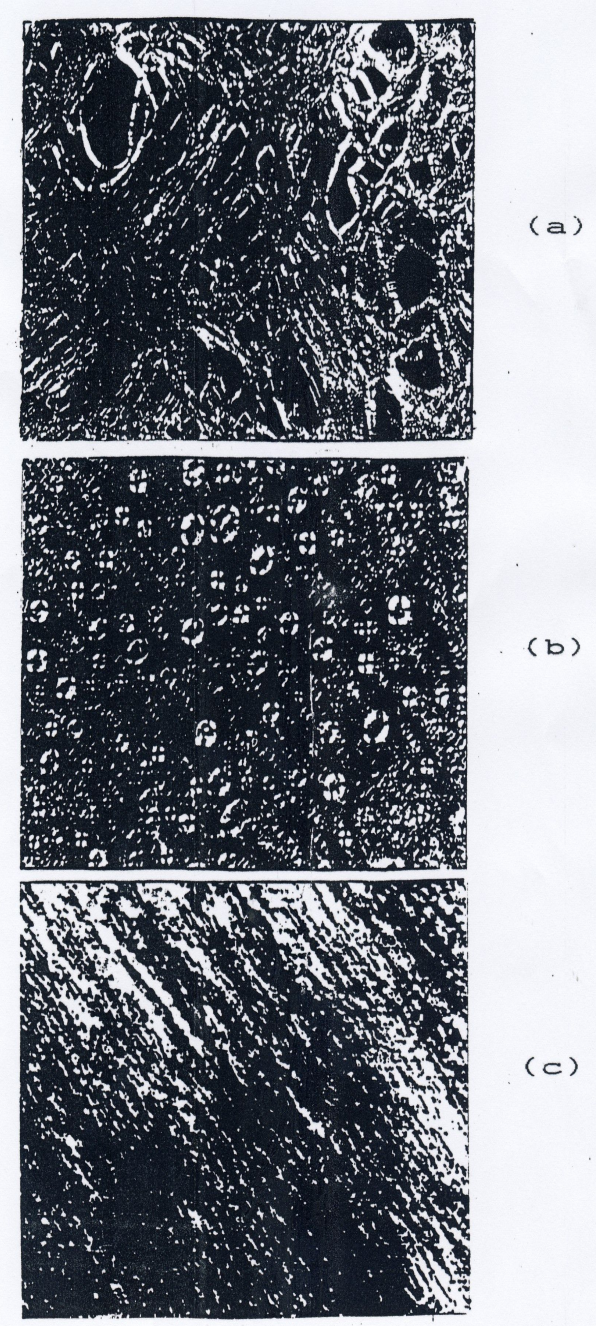

Gambar 3. Tekstur optik dari kristal cair lamelar: (a) oily streak, (b) maltese crosses, (c) fine striations 


\section{DAFTAR PUSTAKA}

1. G. J. T. Tiddy, Phys. Reports, 1980, 1-46.

2. O. Robles-Vasquesz, J. F. A. Saltero, J. E. Pulg, S. B. Tripoli, E. Valles, and O. Manero, J. Colloid Interfece Sci., 160: 6571, (1993).

3. G. T. Dimitrova, Th. F. Thadros, and P. F. Luckman, Langmuir, 11: 1101-1111, (1965).

4. F. Cordobes, J. Munoz and C. Gallegos, $J$. Colloid Interface Sci., 187: 401-417, (1997).

5. H. A. Barnes, Detergents in Rheometry Industrial Applications, K. Walters (Ed.), John Wiley \& Son New York, 33-110.

6. F. Cormelles, J. Caelles, A. Pascual, and J. Sanchaz Leal, $18^{\text {th }}$ International I.F.S.C.C. Congress, Venice, 1994.

7. C. C. Muller-Goyman, Acta Pharm. Technol., 33: 126-130, (1987).

8. S. Engstrom, Lipid Technol., 2: 42-45, (1990).
9. S. E. Friberg, Adv. Colloid Interface Sci., 32: 167-182, (1990).

10. J. D. Mitchell, G. J. T. Tiddy, L. Waring, T. Bostock, and M. P. Modonald, $J$. Chem. Soc. Faraday Trans., 79: 975-991, (1983).

11. J. M. Franco, J. Munov, and C. Gallegos, Langmuir, 16: 8653-8663, (1965).

12. J. E. Moros, F. Cordobes, C. Gallegos and J. M. Franco, J. Dispersion Sci. Technol., 22: 409-420, (2001).

13. A. Amran, Microemulsion, gel process to prepare combination glasses, ( $\mathrm{Ph} . \mathrm{D}$ desertation), Departement of Chemistry, Clarkson University, Potsdam, New York, USA, 1993.

14. N. Moucharafieh, S. E. Friberg, and Larsen, Mol. Cryst. Liquid Crystal (lett), 72: 147, (1982).

15. H. Schinder and J. Seelig, Biochemistry, 14, 1975, 2283.

16. S. E. Friberg, and Buraczewska, Prog. Colloid Polym. Sci., 63: 1, (1978). 